\title{
METHODOLOGICAL APPROACH AS A STRATEGY FOR PROFESSIONAL EMPLOYEES' TRAINING IN SMALL AND MEDIUM SIZED ENTERPRISES IN RUSSIA
}

\author{
Natalia L. Ivanova ${ }^{1}$, Natalia V. Ippolitova ${ }^{2}$ iD, Irina N. Odarich ${ }^{3}$ iD \\ ${ }^{1}$ Tyumen Industrial University (Russia) \\ ${ }^{2}$ Shadrinsk State Pedagogical University (Russia) \\ ${ }^{3}$ Togliatti State University (Russia) \\ NatalieIvanova@yandex.ru,.inv_@mail.ru,azshar2017@mail.ru
}

Received April 2018

Accepted February 2019

\section{Abstract}

In the era of rapid development and the emergence of new methods and ideas for the employees' training in small and medium sized enterprises in Russia, managers need to think about the role that the methodological organization of the educational process, which refers, not only with respect to vocational training, but also in providing the methodological foundation for teaching certain disciplines in small and medium sized enterprises in Russia. The article describes the integrative-praxicological approach in the professional training of employees, it describes the principles and requirements as a methodological basis for the educational process.

Keywords - Small and medium sized enterprises, Vocational Training, Principles, Integration, Praxicology, Employees.

\section{To cite this article:}

Ivanova, N.L., \& Ippolitova, N.V. (2019). Methodological approach as a strategy for professional employees' training in small and medium sized enterprises in Russia. Journal of Technology and Science Education, 9(3), 239-244. https://doi.org/10.3926/jotse.659

\section{Introduction}

When studying the problems of higher professional education, and in connection with the transition of small and medium sized enterprises to a "competence" paradigm, it requires a revision of the methodological approaches that determine the strategy for studying and organizing the professional training of future specialists.

The methodological tools of modern small and medium sized enterprises include a set of ways to gain knowledge about pedagogical approaches. "The methodological approach is a set of ideas that determine the general scientific outlook of the scientist, the principles that form the basis of the research strategy, as well as the methods, techniques, procedures that ensure the implementation of the chosen strategy in practice". An effective-methodological approach, which corresponds to the main trends in the development of vocational education (integration, globalization), is the integrative-praxicological approach. 


\section{Methodology}

To organize and conduct the study, we selected the appropriate tools, presented in the form of two groups of methods. The first group consisted of theoretical methods of research: an analysis that enabled detailed elaboration of the content of various sources of information; synthesis, necessary to obtain the main features and provisions, which subsequently formed the basis for the basic definitions and characteristics of the study. The second group included empirical methods of pedagogical research - the study of literature, which made it possible to find out which aspects of the problem we are studying have been well researched sufficiently; generalization of experience, through which we could logically come to the formulation of concepts.

\section{Results}

The consideration of the philosophical aspects of the integrative-praxicological approach and the determination of its belonging to one of the levels of methodology requires an additional analysis of the approaches affecting the problems of integration and activity. The most general interpretation of integration involves "the uniting of any parts, elements" (Flynn, McKevitt \& Davis, 2015).

In philosophy, "integration means the side of the development process associated with the unification of previously heterogeneous parts and elements. Integration processes can take place both within the existing system - in this case they lead to an increase in the level of its integrity and organization, and when a new system emerges from previously unrelated elements. Individual parts of an integrated whole may have varying degrees of autonomy. In the course of integration processes, the volume and intensity of interrelations and interactions between elements increase in the system" (Sloman, 2017).

"Integrity as a generalized characteristic of objects possessing a complex internal structure expresses the integration, self-sufficiency, autonomy of these objects, and their opposition to the environment, related to their internal activity. The relationship between a part and a whole is characterized by the presence of definite, fixed, multilateral interactions between parts in the whole, having the form of connections. The emergence of links in the formation of the whole of the parts is considered as the primary necessary condition for integration, i.e. the emergence of a new integrity" (Zhou, 2016).

From these positions, integration expresses the dynamics of a complex object, and its integrity is the result of movement. Thus, the study of various phenomena and processes from the standpoint of an integrative approach presupposes a support for the principle of integrativity that characterizes the phenomenon under consideration as an integrity achieved by integrating its constituent elements. The second component of the integrative-praxicological approach is related to the concept of activity (Johnson, 2017).

The analysis of human activity as a complex system from the philosophical point of view reveals the interconnection between the concepts of activity and practice and shows that practice performs an integrative function to the whole system of human activity in all the diversity of its forms and varieties. Important in this case is that all activities have an outlet to practice, enrich its capabilities.

Extrapolating this provision to the psychological and pedagogical aspect of the problem in question, it should be noted that it is in the process of activity that the personality develops, the development of human capabilities, and a necessary condition for this is to include it in a system of interrelated activities.

Analysis of professional human activity involves finding ways to improve its effectiveness, which is the subject of research such a science as praxicology. The founder of praxicology as the theory of effective human activity is the Polish scientist Sonnenstuhl and Trice (2018), who set the task of finding "the general laws of all human activity and deriving the most general rules of such activity". Bell (2016) understands praxicology as a science on the rationality and effectiveness of actions. According to these theories, the structure of activity is linear or networked, the activity process is aimed at achieving the result and must be structured in accordance with the conditions and opportunities to obtain the result (Albrecht, Bakker, Gruman, Macey \& Saks, 2015). 
In view of these provisions, we apply a combination of integrative and praxicological approaches for a holistic analysis of the preparation of employees for professional work (Zuber-Skerritt, 2013).

We define the place of the integrative-praxicological approach in a number of levels of methodological analysis.

This approach cannot be attributed to the level of philosophical methodology as it is not directly connected either with the development of world outlook problems or with the performance of the functions of philosophical criticism of the forms and principles of scientific cognition.

This approach cannot be attributed to the second level of general scientific principles and forms of research, tk. it does not extend simultaneously to the aggregate of fundamental scientific disciplines and is not connected with the solution of a wide range of methodological problems.

It is wrong to consider the integrative-praxicological approach as belonging to the level of methodology and technique of research, it is not a specialized set of procedures ensuring the receipt of a uniform and reliable empirical material and its primary processing (Ogunyomi \& Bruning, 2016).

Proceeding from this, we refer to the integrative-praxicological approach to the third level - the concrete scientific methodology, because, firstly, it relies on a set of approaches and cannot be qualified within one of them when discarding others, and second, presupposes a set of methods and research principles used in psycho-pedagogical, philosophical studies related to pedagogical activity and training of stakeholders for its implementation (Bruhn, Karlan \& Schoar, 2018).

So, the integrative-praxicological approach regards phenomena and processes as complex objects whose integrity is achieved on the basis of the integration of the constituent elements, which are in interrelation and interaction. Characterization of activities and preparation for it from the standpoint of this approach implies the consideration of the first as the main means of achieving the goal of the second. At the same time, preparation for activity is viewed as a system with a certain structure and the existence of interrelations between components. When creating a certain set of conditions, the implementation of this system ensures the achievement of the intended result, increases the efficiency of the functioning of this system (Organization, 2013).

This approach is based on a set of principles that reflect the features of professional training of future specialists as a pedagogical system.

The idea of integrativity, as the basis of this approach, reflects the leading trends of the society as a whole and the higher school in particular. The cardinal changes taking place in modern society are manifested in the integration of various branches of production, deepening the production ties of state and interstate character. The tasks of increasing the efficiency of the production sphere put forward new, higher requirements for specialists and, consequently, the level and quality of their preparation in the process of training at the university. Hence the need to integrate small and medium sized enterprises institutions with other institutions of society. The training of a specialist is objectively conditioned by the needs of modern society.

Socio-economic, scientific-technical, production factors have an increasing influence on pedagogical science. The convergence of science and production in modern society, its transformation into a real productive force, is the basis for the intensification of modern production. The search for new approaches to professional training of university employees is objectively conditioned by the requirements of the developing society. The use of the results of pedagogical research in this area contributes to the intensification of the training of future specialists and the improvement of the quality and effectiveness of the pedagogical process in specific educational institutions.

The development of modern science, and pedagogical science in particular, calls for the integration of interdisciplinary scientific knowledge, the implementation of scientific research on the basis of related sciences, attempts to create concepts and theories reflecting the development of the underlying categories used in related sciences. Formation of holistic ideas about activity, personality, social processes, etc. based on the interpenetration of philosophical, psychological, pedagogical, sociological sciences. The interdisciplinary 
integration of scientific knowledge within the framework of pedagogical science presupposes the assimilation of these related sciences, taking into account the specifics of the objects under study.

The implementation of the praxicological approach in the preparation of future specialists for professional activities presupposes the support of a diverse in the forms and content of the activities of employees, which acts as the main means of achieving the goal of preparation.

Since the activity of employees in the process of professional training is aimed at mastering professional pedagogical activity, it is necessary to consider it from the position of analysis of the pedagogical activity itself. The psychological structure of activity, according to Dreher (2014), is a kind of reflection of the activities of pedagogical systems and contains constructive, organizational, communicative and gnostic components. Accordingly, the activities of employees should be aimed at the development of these components.

It is also important to note that the activity of employees in the process of professional training presupposes a combination of educational, cognitive, educational, practical and independent practical activities. At the same time, educational and cognitive activity acts as a process of solving learning problems aimed at understanding the laws, principles, ways of organizing the learning process and mastering the basics of professional skills. Educational and practical activity is a process of solving practical problems aimed at fulfilling practical tasks in theoretical disciplines that require the application of theoretical knowledge in practice. Independent practical activity presupposes the solution of practical problems in organizing educational work with children on the basis of self-constructing the content and methods of pedagogical activity, understanding their purpose and principles, analyzing and evaluating its results.

The interconnection of these activities is conditioned by the fact that during the training sessions employees acquire a fundamental knowledge of the fundamentals of the theory of general professional disciplines and the basics of professional skills, and in the process of professional practice, actualization, the application of theoretical knowledge in specific conditions, the formation and development of practical skills and skills. Educational and practical activities synthesize cognitive and practical activities of employees, as a result, an interconnected system of knowledge and skills is formed, and their correlation is achieved. The dialectical connection of these activities is achieved through their parallel organization, when, acquiring knowledge, employees use them in solving practical problems, and in practice observe the manifestation of the laws of the pedagogical process, comprehend and generalize knowledge.

In addition to the principles of integrativity and praxicology, other principles are also based on the integrative-praxicological approach.

The principle of adequacy of the content of vocational training of future specialists to the requirements of modern society, meaning the need to determine the content of professional training of employees, taking into account modern methodological approaches, new concepts of vocational training and upbringing, changes in the technology of the pedagogical process.

The principle of helicity, which combines the elements of linear and concentric construction of curricula and programs for professional employees' training, involves the mastering of knowledge and the formation of skills and skills not only in a certain sequence, but also mastering their complex with the complexity of the system of knowledge and specific skills at various levels of training.

The principle of variability reflects, on the one hand, the need for continuous development, improvement of the foundations of professional pedagogical training on the basis of taking into account changes occurring in society, the system of small and medium sized enterprises in Russia, and on the other hand, it presupposes a multiplicity of ways of preparation depending on the contingent of employees, the level of vocational training, local conditions and etc.

The principle of algorithmization means the implementation of the training of employees for professional activity on the basis of mastering various algorithms of pedagogical activity corresponding to various situations. "An algorithm is a rule or an action program for obtaining the desired result under given conditions. By the degree of accuracy of the task, mechanical and non-mechanical (variational, flexible) 
algorithms are distinguished. The latter, in turn, are subdivided into stochastic (probabilistic) and heuristic algorithms. As the author notes, any activity can be really algorithmized only to the extent that the standards are realized by the subject of activity, are explicated, socially approved and fixed in the subject's knowledge".

For professional activities, mechanical, rigid stochastic and heuristic algorithms may be characteristic, reflecting the creative nature of the activity, the uniqueness and sometimes unpredictability of each particular pedagogical situation. In the professional training of future specialists in the oil and gas industry, for example, the use of algorithms is fully justified, since it teaches them to analyze and take into account the various conditions for choosing methods and methods of action in each specific situation. Important in this case is not only awareness of the impossibility of using rigid algorithms in professional activity, but also mastering them of stochastic and heuristic algorithms in the process of teaching, cognitive, educational and self- practice.

Algorithmicity in mastering the knowledge, skills and skills necessary for professional activities, contributes to improving employees' readiness to implement all the functions of a specialist in conditions of independent professional activity.

\section{Conclusions}

Thus, the implementation of the praxicological aspect of the integrative-praxicological approach in the preparation of employees for professional activity presupposes: taking into account the components of the psychological structure of this activity (constructive, organizational, communicative, gnostic) when it is mastered by employees; realization in interrelation of various types of educational activity of employees in the process of training (educational-cognitive, educational-practical, independent practical), contributing to mastering the dialectical unity of theoretical knowledge and practical skills and skills necessary for any professional activity.

Taking into account all the above, it is possible to single out the requirements for an integrative-praxicological approach:

A. Ensuring the integration of the various components of professional training of future specialists.

B. Ensuring the unity of the assimilation of theoretical knowledge and the formation of practical skills and skills by employees on the basis of their inclusion in a variety of types and content of activities.

C. Ensuring that employees master the algorithms of pedagogical activity in the process of their professional training.

Concluding the analysis of the essence of integrative-praxicological approach to the organization of professional training of future specialists, it is necessary to note the following. This approach means that the process of professional training of employees is seen as a holistic phenomenon, consisting of elements that are in a relationship of interdependence and interdependence, which ensures their integration into a single whole one. A variety of employees' activities is the main means of achieving its goal in the process of professional training.

\section{Declaration of Conflicting Interests}

The author declared no potential conflicts of interest with respect to the research, authorship, and/or publication of this article.

\section{Funding}

The author received no financial support for the research, authorship, and/or publication of this article.

\section{References}

Albrecht, S.L., Bakker, A.B., Gruman, J.A., Macey, W.H., \& Saks, A.M. (2015). Employee engagement, human resource management practices and competitive advantage: An integrated approach. Journal of Organizational Effectiveness: People and Performance, 2, 7-35. https://doi.org/10.1108/JOEPP-08-2014-0042 
Bell, R. (2016). Unpacking the link between entrepreneurialism and employability: An assessment of the relationship between entrepreneurial attitudes and likelihood of graduate employment in a professional field. Education + Training. 58, 2-17. https://doi.org/10.1108/ET-09-2014-0115

Bruhn, M., Karlan, D., \& Schoar, A. (2018). The impact of consulting services on small and medium enterprises in Russia: Evidence from a randomized trial in Mexico. Journal of Political Economy, 126, 635-687. https://doi.org/10.1086/696154

Dreher, S. (2014). Social media and the world of work: A strategic approach to employees' participation in social media. Corporate Communications: An International Journal, 19, 344-356.

Flynn, A., McKevitt, D., \& Davis, P. (2015). The impact of size on small and medium-sized enterprise public sector tendering. International Small Business Journal, 33, 443-461.

https://doi.org/10.1177/0266242613503178

Johnson, M.P. (2017). Knowledge acquisition and development in sustainability-oriented small and medium-sized enterprises in Russia: Exploring the practices, capabilities and cooperation. Journal of cleaner production, 142, 3769-3781. https://doi.org/10.1016/j.jclepro.2016.10.087

Ogunyomi, P., \& Bruning, N.S. (2016). Human resource management and organizational performance of small and medium enterprises (SMEs) in Nigeria. The International Journal of Human Resource Management, 27, 612-634. https://doi.org/10.1080/09585192.2015.1033640

Organization, W.H. (2013). Transforming and scaling up health professionals' education and training: World Health Organization guidelines 2013. World Health Organization.

Sloman, M. (2017). A handbook for training strategy. Routledge. https:// doi.org/10.4324/9781315263908

Sonnenstuhl, W.J., \& Trice, H.M. (2018). Strategies for employee assistance programs: The crucial balance. Cornell University Press.

Zhou, B. (2016). Lean principles, practices, and impacts: a study on small and medium-sized enterprises (SMEs). Annals of Operations Research, 241, 457-474. https://doi.org/10.1007/s10479-012-1177-3

Zuber-Skerritt, O. (2013). Professional development in bigher education: A theoretical framework for action research. Routledge.

Published by OmniaScience (www.omniascience.com)

Journal of Technology and Science Education, 2019 (www.jotse.org)

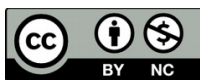

Article's contents are provided on an Attribution-Non Commercial 4.0 Creative commons International License. Readers are allowed to copy, distribute and communicate article's contents, provided the author's and JOTSE journal's names are included. It must not be used for commercial purposes. To see the complete licence contents, please visit https://creativecommons.org/licenses/by-nc/4.0/. 